\title{
Unified Traction and Battery Charging Systems for Electric Vehicles: A Sustainability Perspective
}

Tiago J. C. Sousa ${ }^{1}$, Luís Machado ${ }^{1}$, Delfim Pedrosa ${ }^{1}$, Vítor Monteiro ${ }^{1}$, João L. Afonso ${ }^{1}$

${ }^{1}$ Centro ALGORITMI, University of Minho, Campus de Azurém, Guimarães, Portugal

tsousa@dei.uminho.pt

\begin{abstract}
This paper presents an analysis of unified traction and battery charging systems for electric vehicles (EVs), both in terms of operation modes and in terms of implementation cost, when compared to dedicated solutions that perform the same operation modes. Regarding the connection of the EV battery charging system with the power grid, four operation modes are analyzed: (1) Grid-to-Vehicle (G2V); (2) Vehicle-to-Grid (V2G); (3) Vehicle-to-Home (V2H); and (4) Vehicle-for-Grid (V4G). With an EV unified system, each of these operation modes can be used in single-phase and three-phase power grids. Furthermore, a cost estimation is performed for an EV unified system and for dedicated systems that can perform the same functionalities, in order to prove the benefits of the EV unified approach. The cost estimation comprises two power levels, namely $6 \mathrm{~kW}$, single-phase, related to domestic installations, and $50 \mathrm{~kW}$, three-phase, related to industrial installations. The relevance of unified traction and battery charging systems for EVs is proven for single-phase and three-phase power grids.
\end{abstract}

Keywords: Electric Vehicle, Unified System, Smart Grids, Cost Estimation.

\section{Introduction}

Electric Vehicles (EVs) represent a growing alternative to the conventional fossil fuel powered vehicles towards the reduction of greenhouse emissions at the utilization level, as well as the refraining of fossil resources exploitation [1], [2]. The conjugation of EVs and renewable energy sources represents one major role towards smart grids, with the bidirectional operation for EVs offering new operation modes and grid supporting functionalities [3]-[5]. Hence, the typical EV battery charging operation (Grid-to-Vehicle $\mathrm{G} 2 \mathrm{~V}$ ) can be extended to the Vehicle-to-Grid (V2G) operation mode, initially proposed in [6]. Furthermore, other operation modes for the EV have been proposed in the literature, such as Vehicle-to-Home (V2H), where the EV acts as a voltage source for an electrical installation, and Vehicle-for-Grid (V4G), where the EV acts as an active power conditioner, i.e., a Shunt Active Power Filter (SAPF) [7]-[11].

The referred functionalities are accomplished with an on-board EV battery charger, which is limited to power levels below $19.2 \mathrm{~kW}$ in the best-case scenario [12]. However, with integrated EV battery chargers, i.e., a unified system for traction and battery charging of an EV [13]-[15], higher power levels are achievable, since the maximum power is dictated by the traction system nominal power, which is typically several dozens or 
few hundreds of $\mathrm{kW}$ for automobiles. This allows the battery charging operation with higher power levels, as well as the other referred operation modes, making it possible to operate in industrial installations, for instance. Moreover, since all the referred operation modes are accomplished with a single system, the use of dedicated equipment for each operation can be discarded, e.g., Load Shift System (LSS) or SAPF.

In this context, this paper presents the advantages of unified traction and battery charging systems for EVs, both in terms of operation modes and in terms of implementation cost, when compared to dedicated solutions that perform the same operation modes. Hence, four operation modes are analyzed: (1) Grid-to-Vehicle (G2V); (2) Vehicle-to-Grid (V2G); (3) Vehicle-to-Home (V2H); and (4) Vehicle-for-Grid (V4G). With a unified system, each of these operation modes can be used in single-phase and three-phase power grids. Furthermore, a cost estimation is performed for a unified system and for dedicated systems that can perform the same functionalities, namely a LSS and a SAPF, in order to prove the benefits of the EV unified approach.

The paper is structured as follows: Section 2 presents the operation modes under analysis, as well as simulation results of each one; Section 3 presents a cost estimation and comparison with conventional dedicated solutions; finally, Section 4 draws the conclusions of this paper.

\section{Operation Modes}

This section shows the operation modes considered for the EV in the scope of this paper, which are the following: (1) Grid-to-Vehicle (G2V); (2) Vehicle-to-Grid (V2G); (3) Vehicle-to-Home (V2H); and (4) Vehicle-for-Grid (V4G). All the referred operation modes encompass the connection of the EV to an electrical installation, which can be either single-phase or three-phase. Fig. 1 shows a block diagram of the general connection of the EV to an electrical installation with the referred operation modes. It should be noted that all the operation modes take in consideration high levels of power quality, which is a relevant feature for smart grids. In the scope of this paper, only the front-end ac-dc converter operation is analyzed.

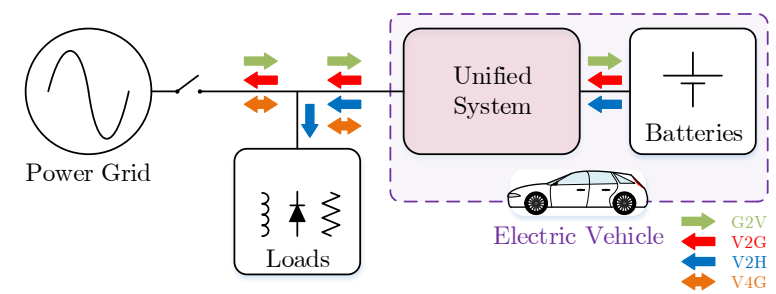

Fig. 1. Block diagram of the EV connection to an ac electrical installation.

\subsection{Grid-to-Vehicle (G2V)}

The traditional operation of an on-board EV battery charger, i.e., charging the batteries with power provided by the power grid, is commonly referred as G2V. Fig. 2 shows a 
block diagram of this operation mode. The battery charging performed by on-board EV battery chargers is typically classified as slow, since the power level of these systems is limited to $19.2 \mathrm{~kW}$, as previously referred. On the other hand, by using a unified system for traction and battery charging, higher power levels can be used in the battery charging operation, hence equipping the EV with an on-board fast battery charger. With this system, both slow and fast battery charging are possible, which are accomplished by connecting the EV to single-phase and three-phase power grids, respectively.

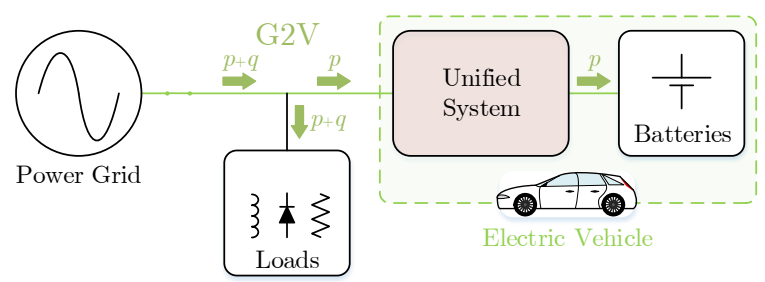

Fig. 2. Block diagram of the Grid-to-Vehicle (G2V) operation mode.

Fig. 3 shows a simulation result of this operation mode for an operating power of $3.2 \mathrm{~kW}$ (slow battery charging, single-phase), where it can be seen the power grid voltage $\left(v_{g}\right)$ and current $\left(i_{g}\right)$ and the dc-link voltage $\left(v_{d c}\right)$. It can be seen that $v_{g}$ is not sinusoidal, but the system is capable of absorbing a sinusoidal current $i_{g}$ in phase with $v_{g}$, aiming for a practically unitary power factor. Besides, $v_{d c}$ is controlled to the established reference average value of $400 \mathrm{~V}$.

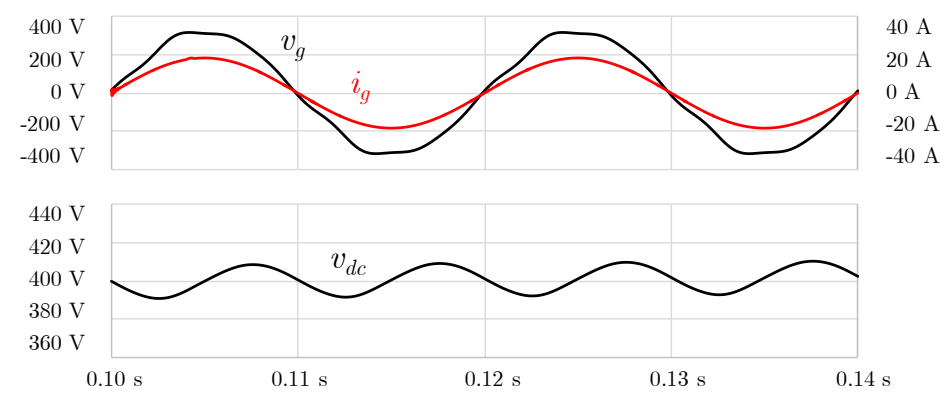

Fig. 3. Simulation results of the G2V operation mode for a power of $3.2 \mathrm{~kW}$ (single-phase):

Power grid voltage $\left(v_{g}\right)$, power grid current $\left(i_{g}\right)$ and dc-link voltage $\left(v_{d c}\right)$.

In order to verify the fast battery charging capability of a unified system, Fig. 4 shows a result of the $\mathrm{G} 2 \mathrm{~V}$ operation mode for an operating power of $50 \mathrm{~kW}$ (fast battery charging, three-phase), where the phase-neutral voltages $\left(v_{g a}, v_{g b}, v_{g c}\right)$, the phase currents $\left(i_{g a}\right.$, $\left.i_{g b}, i_{g c}\right)$ and the dc-link voltage $\left(v_{d c}\right)$ can be seen. Also, in this case, each phase current is sinusoidal and in phase with the respective phase-neutral voltage, even if the voltage is not sinusoidal. In this case, $v_{d c}$ is controlled to the established reference average value of $800 \mathrm{~V}$. 


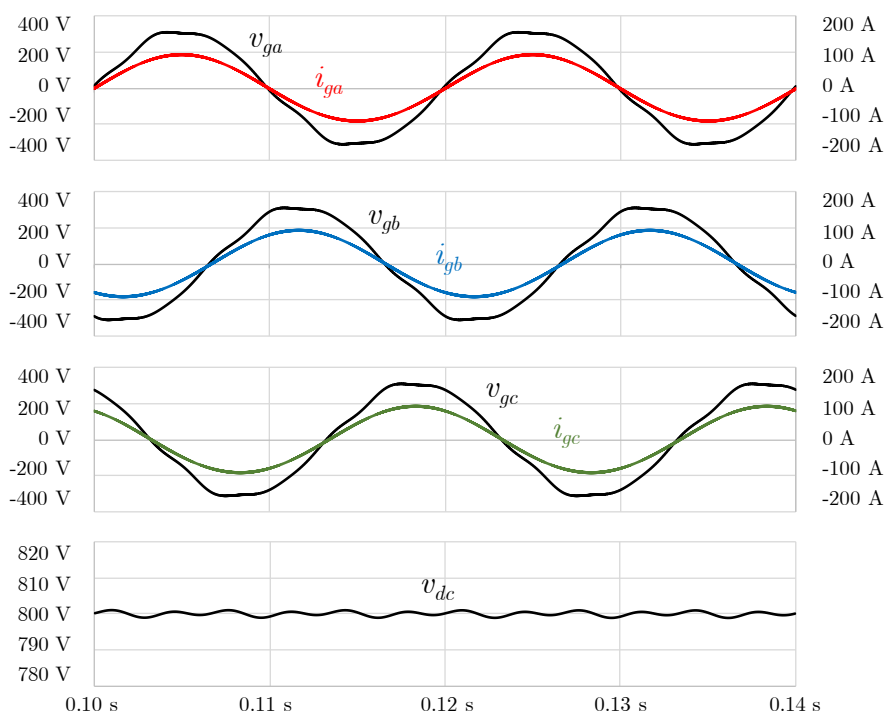

Fig. 4. Simulation results of the G2V operation mode for a power of $50 \mathrm{~kW}$ (three-phase): Power grid voltages $\left(v_{g x}\right)$, power grid currents $\left(i_{g x}\right)$ and dc-link voltage $\left(v_{d c}\right)$.

\subsection{Vehicle-to-Grid (V2G)}

The V2G operation mode consists in delivering energy, previously stored in the EV batteries, back to the power grid. This operation mode, whose block diagram can be seen in Fig. 5, represents a promising benefit for smart grids in the sense that it endows the EV with auxiliary functions to the power grid. Moreover, the combination of G2V and V2G operation modes allows the EV to operate as a LSS. These functions can be accomplished with a conventional bidirectional on-board EV battery charger, with the main difference relatively to a unified system being the admissible power levels for operation. Therefore, the unified system considered in this paper encompasses the V2G operation mode both in single-phase and three-phase power grids, allowing grid support functionalities, for instance, in domestic and industrial electrical installations.

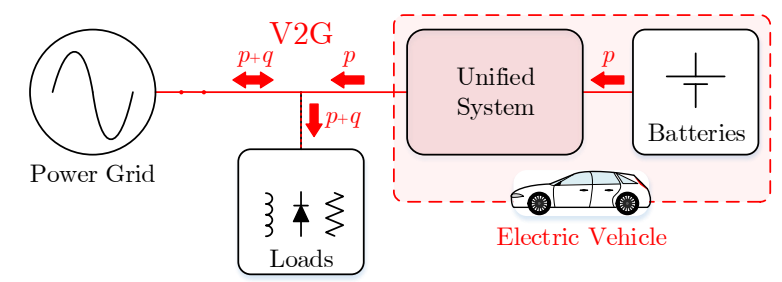

Fig. 5. Block diagram of the Vehicle-to-Grid (V2G) operation mode. 
Fig. 6 shows a simulation result of the V2G operation mode for an operating power of $3.2 \mathrm{~kW}$ (single-phase), which can be accomplished with almost any bidirectional battery charger. In this case, the power grid current $\left(i_{g}\right)$ is also sinusoidal, but in phase opposition with the power grid voltage $\left(v_{g}\right)$, meaning that the EV battery charger is operating as a power source. Besides, the phase shift between these two quantities is practically $180^{\circ}$, meaning a practically unitary power factor.

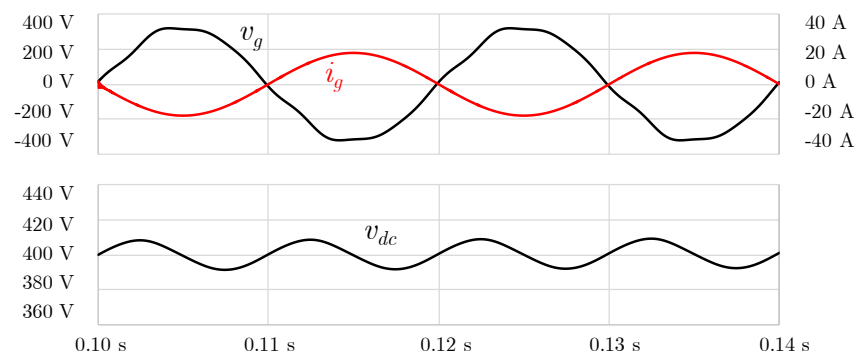

Fig. 6. Simulation results of the V2G operation mode for a power of $3.2 \mathrm{~kW}$ (single-phase)

Power grid voltage $\left(v_{g}\right)$, power grid current $\left(i_{g}\right)$ and dc-link voltage $\left(v_{d c}\right)$.

Similarly to the previous case, the V2G operation mode can be performed in three-phase power grids, for higher power levels. Fig. 7 shows this operation with a power of $50 \mathrm{~kW}$ (three-phase), where it can be seen the phase-neutral voltages $\left(v_{g a}, v_{g b}\right.$, $\left.v_{g c}\right)$, the phase currents $\left(i_{g a}, i_{g b}, i_{g c}\right)$ and the dc-link voltage $\left(v_{d c}\right)$. Once again, the injected currents are sinusoidal and in phase opposition with the respective voltages, aiming for a unitary power factor.

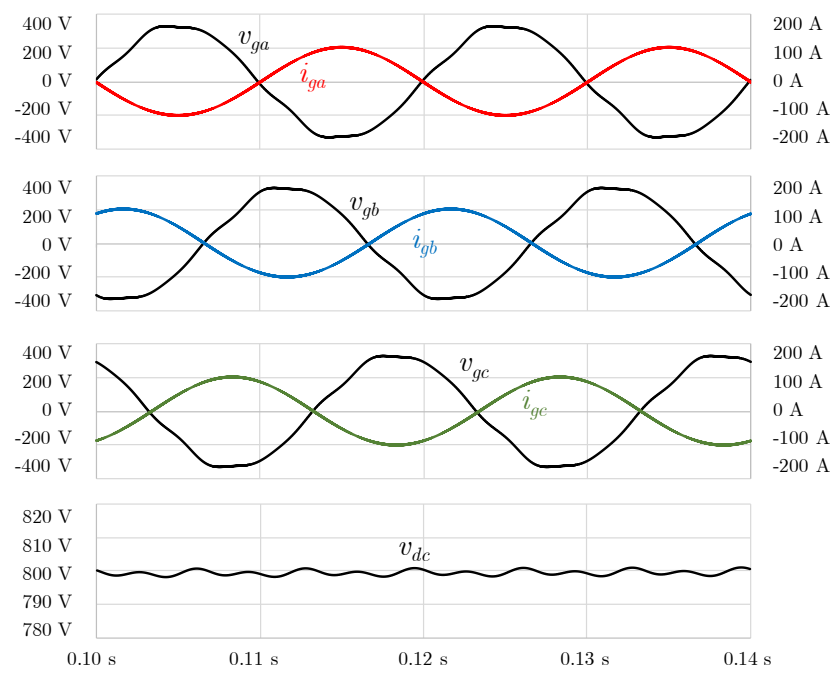

Fig. 7. Simulation results of the V2G operation mode for a power of $50 \mathrm{~kW}$ (three-phase): Power grid voltages $\left(v_{g x}\right)$, power grid currents $\left(i_{g x}\right)$ and dc-link voltage $\left(v_{d c}\right)$. 


\section{$2.3 \quad$ Vehicle-to-Home (V2H)}

The V2H operation mode, whose block diagram can be seen in Fig. 8, consists in the $\mathrm{EV}$ acting as a voltage source for the electrical installation, disconnecting the installation from the upstream grid and supplying the loads with energy stored in the EV batteries. This operation mode can be initiated either in a planned way, such as in LSSs, or triggered by disturbances in the power grid voltage, i.e., overvoltages or undervoltages, similarly to an off-line uninterruptible power supply (UPS). Therefore, by comprising unified systems for traction and battery charging, EVs can act as off-line UPSs in both domestic and industrial installations, which can avoid the use of dedicated UPSs when the EV is parked.

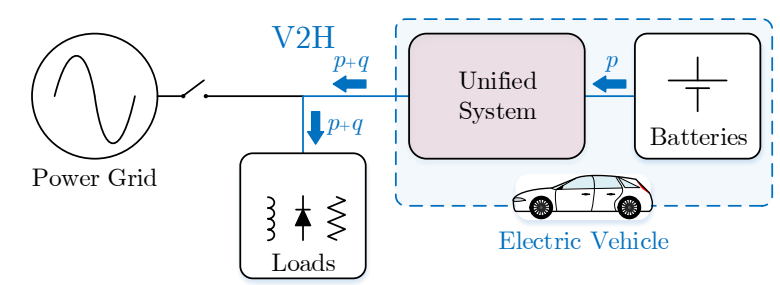

Fig. 8. Block diagram of the Vehicle-to-Home (V2H) operation mode.

Fig. 9 shows the V2H operation mode initiated in a planned way, similarly to a LSS when used for self-consumption (single-phase). As it can be seen, the EV battery charger produces a $230 \mathrm{~V}, 50 \mathrm{~Hz}$ ac voltage $\left(v_{e v}\right)$ that is practically sinusoidal even with a distorted current consumption $\left(i_{e v}\right)$, which is drawn by a linear RL load and a nonlinear diode bridge rectifier with capacitive filter, absorbing a combined power of $5.3 \mathrm{~kW}$. For this operation, due to the increased ripple in the dc-link voltage $\left(v_{d c}\right)$ as a consequence of distorted current consumption (approximately $40 \mathrm{~V}$ peak-to-peak in this case), its reference value was slightly increased compared to the previous reference value of $400 \mathrm{~V}$, hereby being established the value of $450 \mathrm{~V}$.

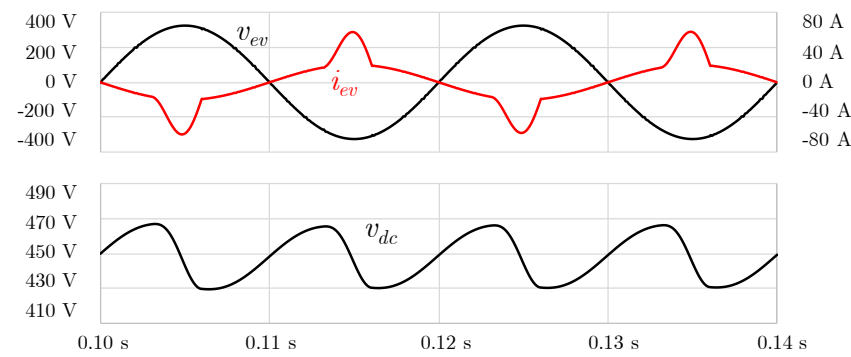

Fig. 9. Simulation results of the V2H operation mode for a power of $5.3 \mathrm{~kW}$ (single-phase): Produced ac voltage $\left(v_{e v}\right)$, absorbed current $\left(i_{e v}\right)$ and dc-link voltage $\left(v_{d c}\right)$.

Fig. 10 shows the V2H operation mode for three-phase installations, with an operating power of $30 \mathrm{~kW}$ drawn by the same two types of load as the previous case. This figure 
shows the produced ac voltages $\left(v_{e v a}, v_{e v b}, v_{e v c}\right)$, the respective consumed currents $\left(i_{\text {eva }}\right.$, $\left.i_{e v b}, i_{e v c}\right)$ and the dc-link voltage $\left(v_{d c}\right)$. Similarly to the previous case, the produced voltages are sinusoidal with the desired amplitude even with distorted current consumption.

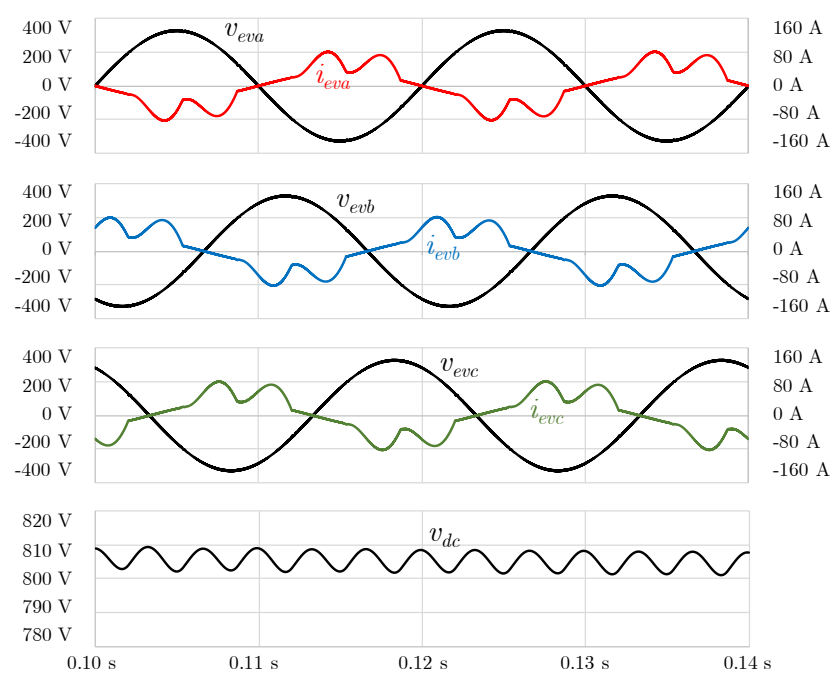

Fig. 10. Simulation results of the V2H operation mode for a power of $30 \mathrm{~kW}$ (three-phase):

Produced ac voltages $\left(v_{e v x}\right)$, absorbed currents $\left(i_{e v x}\right)$ and dc-link voltage $\left(v_{d c}\right)$.

\subsection{Vehicle-for-Grid (V4G)}

The V4G operation mode consists in the compensation of power quality problems to the electrical installation where the vehicle is connected to. This operation mode can be performed simultaneously with either the operation modes G2V or V2G, as the bidirectional arrows of Fig. 11 suggest. The main difference between the V4G and the regular G2V or V2G operation modes resides in the current, absorbed or injected from the power grid. The current is sinusoidal in G2V and V2G operation modes, while in V4G the purpose is to guarantee a sinusoidal grid current and in phase with the voltage, i.e., with the EV acting as a SAPF. Once again, with a unified system, this operation mode can be accomplished in single-phase and three-phase installations, allowing power conditioning functionalities in both domestic and industrial facilities.

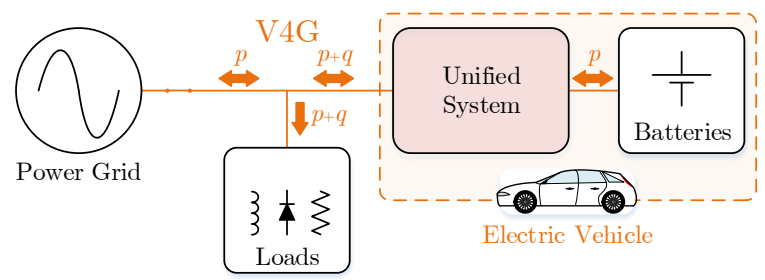

Fig. 11. Block diagram of the Vehicle-for-Grid (V4G) operation mode. 
Fig. 12 shows the V4G operation mode in single-phase installations for two different scenarios, with Fig. 12 (a) showing the combination of V4G and G2V and Fig. 12 (b) showing the combination of V4G and V2G. In both cases, the connected loads (a linear $\mathrm{RL}$ and a nonlinear diode bridge rectifier with capacitive filter) present a power consumption of $1.5 \mathrm{~kW}$. Both figures show the power grid voltage $\left(v_{g}\right)$, the load current $\left(i_{l d}\right)$, the current produced by the EV battery charger $\left(i_{e v}\right)$, the resulting grid current $\left(i_{g}\right)$ and the dc-link voltage $\left(v_{d c}\right)$.

In Fig. 12 (a), the EV batteries are being charged with a power of $3 \mathrm{~kW}$. In order to perform the V4G operation, the current absorbed by the EV battery charger is not sinusoidal, but contains the necessary harmonic distortion to obtain a sinusoidal current from the power grid point of view. As it can be seen, the current $i_{g}$ is sinusoidal and in phase with the voltage $v_{g}$.

In Fig. 12 (b), the EV batteries are being discharged with a power of $3 \mathrm{~kW}$. Once again, the current injected by the EV battery charger is not sinusoidal in order to perform the V4G operation. As it can be seen, the current $i_{g}$ is sinusoidal and in phase opposition with $v_{g}$, meaning that energy is being delivered into the power grid with unitary power factor. This happens because the power delivered by the EV battery charger is higher than the power consumed by the loads, otherwise the resulting current $i_{g}$ would be in phase with $v_{g}$, i.e., the power grid would have to provide the power difference to supply the loads. Hence, the power grid is absorbing $1.5 \mathrm{~kW}$.

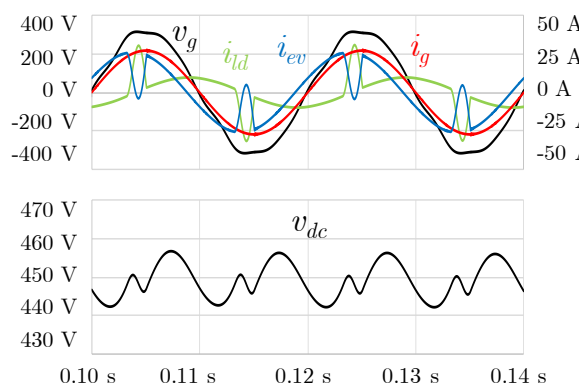

(a)

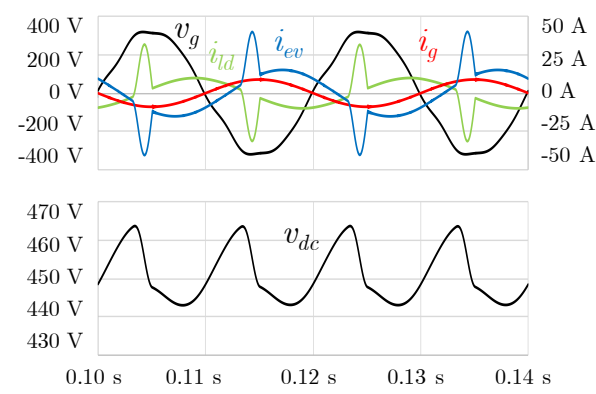

(b)

Fig. 12. Simulation results of the V4G operation mode (single-phase), with $3 \mathrm{~kW}$ battery power and $1.5 \mathrm{~kW}$ load power, combined with: (a) G2V; (b) V2G.

Fig. 13 shows the same operation mode in a three-phase power grid, where it can be seen the power grid voltages $\left(v_{g a}, v_{g b}, v_{g c}\right)$, the load currents $\left(i_{l d a}, i_{l d b}, i_{l d c}\right)$, the currents produced by the EV battery charger $\left(i_{e v a}, i_{e v b}, i_{e v c}\right)$, the resulting grid currents $\left(i_{g a}, i_{g b}\right.$, $\left.i_{g c}\right)$ and the dc-link voltage $\left(v_{d c}\right)$. In both cases, the loads absorb a power of $10 \mathrm{~kW}$.

Fig. 13 (a) shows the combination of V4G and G2V operation modes, where the EV batteries are being charged with $30 \mathrm{~kW}$. As it can be seen, the EV battery charger consumes distorted currents so that the power grid currents are sinusoidal and in phase with the respective voltages.

Fig. 13 (b) shows the combination of V4G and V2G operation modes, where the EV batteries are being discharged with $30 \mathrm{~kW}$. Once again, the currents produced by the EV battery charger are distorted, turning the power grid currents sinusoidal and in phase 
opposition with the respective voltages. Since the EV battery charger delivers $30 \mathrm{~kW}$ and the loads absorb $10 \mathrm{~kW}$, the power grid is receiving $20 \mathrm{~kW}$, therefore its currents are in phase opposition with the corresponding voltages.

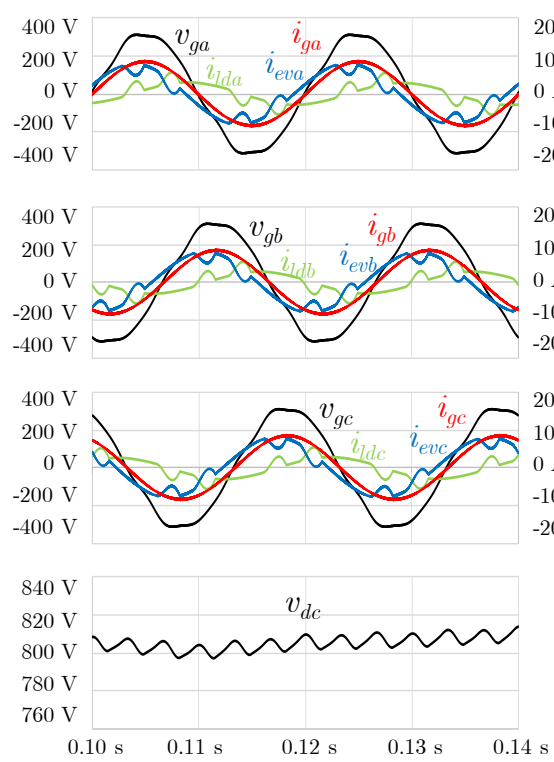

(a)

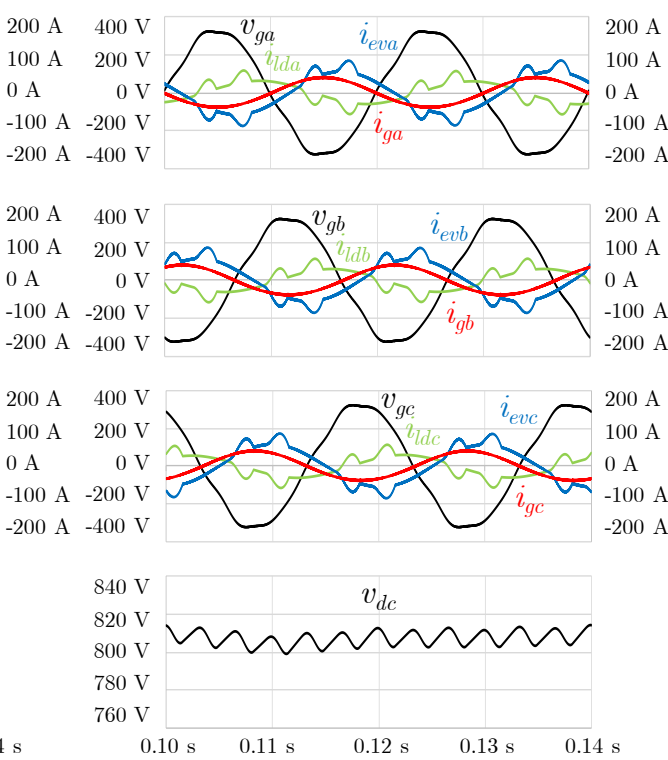

(b)

Fig. 13. Simulation results of the V4G operation mode (three-phase), with $30 \mathrm{~kW}$ battery power and $10 \mathrm{~kW}$ load power, combined with: (a) G2V; (b) V2G.

\section{Cost Comparison with Conventional Solutions}

This section presents a comparison of an EV equipped with a unified system for traction and battery charging with the conventional dedicated systems for performing the abovementioned functionalities. Hence, an average cost estimation of a LSS and a SAPF is performed for two power ratings, namely $6 \mathrm{~kW}$ (single-phase) and $50 \mathrm{~kW}$ (three-phase), in order to compare with the slow and fast EV battery charging operation, respectively.

In terms of power electronics converters, a SAPF basically comprises an ac-dc converter. On the other hand, a LSS comprises the same structure, plus a dc-dc converter and the energy storage elements that are indispensable in a LSS, mostly based on lead acid or li-ion batteries [16]-[19]. However, the storage elements were discarded from the cost estimation, since that would require a more detailed and complex analysis regarding EVs.

Thereupon, Fig. 14 depicts a cost estimation of the power converters necessary to implement a SAPF (red) and a LSS (blue) for a $6 \mathrm{~kW}$ power rating (Fig. 14 (a)) and for a $50 \mathrm{~kW}$ power rating (Fig. 14 (b)). It should be referred that the presented cost values are average values of a wide value range, since a power converter cost can depend on 
the topology of implementation, semiconductor approach, type of sensors, capacitor technology, among others. Besides, the prices vary with the retailer and with the quantity, with small quantities being considered in this case. As it can be seen, the LSS power stage has a slightly higher cost due to the additional dc-dc converter to interface the ac-dc converter dc-link with the energy storage system. The cost estimation of the power converters for a $50 \mathrm{~kW}$ LSS is also valid for an EV unified system, since the structure is the same.

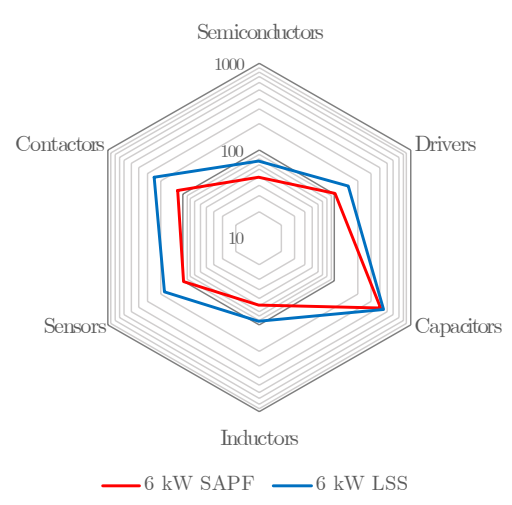

(a)

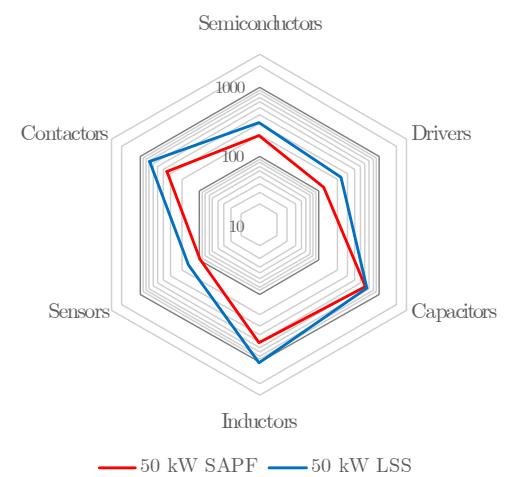

(b)

Fig. 14. Cost estimation of the power electronics converters for a Shunt Active Power Filter (SAPF) (red) and for a Load Shift System (LSS) (blue) considering a power rating of: (a) $6 \mathrm{~kW}$ (single-phase); (b) $50 \mathrm{~kW}$ (three-phase).

The total cost estimation of the power electronics converters for a SAPF, LSS and EV unified system can be seen in Table 1, both for $6 \mathrm{~kW}$ and $50 \mathrm{~kW}$. As previously referred, the LSS and the EV unified system present the same average cost, which is the higher cost in the table ( $3040 €$ ). However, the EV can perform the same functionalities of the SAPF for the same power, without adding extra $1870 €$, besides being able to operate as a UPS. Moreover, the EV unified system can be seen as a mobile power electronics system, for instance, operating at home during the night and operating in a higher power installation during the day (i.e., at work), being able to perform the functionalities of two separate systems.

From this, it can be seen that the EV has an important role in power grids, being able to concentrate several operation modes in a single equipment, and it has even more relevance when a unified traction and battery charging system is used. It should be noted that this analysis only concerns the acquisition costs of the power electronics converters, not considering the battery costs. Besides, the analysis does not consider the investment payback that can be attained (e.g., with load shift operation), neither considers battery aging, which is a relevant issue in EVs. Nevertheless, the investment of an EV is already advantageous, both economically, environmentally and for the power grid, as long as its battery charger is capable of operating with good characteristics (i.e., sinusoidal current and bidirectional operation), and it can be even more advantageous when renewable energy sources are integrated. Accordingly, the advantages 
of the EV can be extended from households to industrial facilities if its EV battery charger is able to operate with higher power levels, i.e., by using a unified traction and battery charging system.

Table 1. Total cost estimation of the SAPF, LSS and EV unified system.

\begin{tabular}{|c|c|c|}
\hline & Single-phase (6 kW) & Three-phase (50 kW) \\
\hline SAPF & $650 €$ & $1870 €$ \\
\hline LSS & $900 €$ & $3040 €$ \\
\hline EV Unified System & - & $3040 €$ \\
\hline
\end{tabular}

\section{Conclusions}

This paper presented an analysis of a unified traction and battery charging system for electric vehicles (EVs) and its different possibilities in terms of operation modes. Four operation modes were analyzed considering the connection of the EV battery charger to the power grid: (1) Grid-to-Vehicle (G2V); (2) Vehicle-to-Grid (V2G); (3) Vehicle-to-Home (V2H); and (4) Vehicle-for-Grid (V4G). Each operation mode can be performed both in single-phase and three-phase power grids, and simulation results verified the correct operation of each mode. Moreover, a cost estimation was performed, comparing the EV unified system with dedicated solutions, namely a Load Shift System (LSS) and a Shunt Active Power Filter (SAPF) for two power levels: $6 \mathrm{~kW}$ - related to domestic installations and slow battery charging operation; and $50 \mathrm{~kW}$ - related to industrial installations and fast battery charging operation. The cost estimation and the different possible operation modes prove that an EV with a unified system can play a relevant role in single-phase and three-phase power grids, and it can be even more relevant considering the paradigm of smart grids.

\section{Acknowledgments}

This work has been supported by FCT - Fundação para a Ciência e Tecnologia within the Project Scope: UID/CEC/00319/2019. This work has been supported by the FCT Project DAIPESEV PTDC/EEI-EEE/30382/2017, and by the FCT Project newERA4GRIDs PTDC/EEI-EEE/30283/2017.

\section{References}

1. C. C. Chan and Y. S. Wong, "Electric vehicles charge forward," IEEE Power and Energy Magazine, vol. 2, no. 6, pp. 24-33, Nov. 2004.

2. J. Milberg and A. Schlenker, "Plug into the Future," IEEE Power and Energy Magazine, vol. 9, no. 1, pp. 56-65, Jan. 2011.

3. J. Ansari, A. Gholami, A. Kazemi, and M. Jamei, "Environmental/economic dispatch incorporating renewable energy sources and plug-in vehicles," IET Generation, Transmission \& Distribution, vol. 8, no. 12, pp. 2183-2198, Dec. 2014. 
4. K. Knezovic, S. Martinenas, P. B. Andersen, A. Zecchino, and M. Marinelli, "Enhancing the Role of Electric Vehicles in the Power Grid: Field Validation of Multiple Ancillary Services," IEEE Transactions on Transportation Electrification, vol. 3, no. 1, pp. 201-209, 2017.

5. H. N. T. Nguyen, C. Zhang, and J. Zhang, "Dynamic Demand Control of Electric Vehicles to Support Power Grid With High Penetration Level of Renewable Energy," IEEE Transactions on Transportation Electrification, vol. 2, no. 1, pp. 66-75, Mar. 2016.

6. W. Kempton and J. Tomić, "Vehicle-to-grid power implementation: From stabilizing the grid to supporting large-scale renewable energy," Journal of Power Sources, vol. 144, no. 1, pp. 280-294, 2005.

7. V. Monteiro, J. G. Pinto, and J. L. Afonso, "Operation Modes for the Electric Vehicle in Smart Grids and Smart Homes: Present and Proposed Modes," IEEE Transactions on Vehicular Technology, vol. 65, no. 3, pp. 1007-1020, Mar. 2016.

8. V. Monteiro, B. Exposto, J. C. Ferreira, and J. L. Afonso, "Improved Vehicle-to-Home (iV2H) Operation Mode: Experimental Analysis of the Electric Vehicle as Off-Line UPS," IEEE Transactions on Smart Grid, vol. 8, no. 6, pp. 2702-2711, 2017.

9. S. Su et al., "Reactive power compensation using electric vehicles considering drivers' reasons," IET Generation, Transmission \& Distribution, vol. 12, no. 20, pp. 4407-4418, Nov. 2018.

10. M. Kesler, M. C. Kisacikoglu, and L. M. Tolbert, "Vehicle-to-Grid Reactive Power Operation Using Plug-In Electric Vehicle Bidirectional Offboard Charger," IEEE Transactions on Industrial Electronics, vol. 61, no. 12, pp. 6778-6784, Dec. 2014.

11. R. Hou and A. Emadi, "Applied Integrated Active Filter Auxiliary Power Module for Electrified Vehicles With Single-Phase Onboard Chargers," IEEE Transactions on Power Electronics, vol. 32, no. 3, pp. 1860-1871, Mar. 2017.

12. M. Yilmaz and P. T. Krein, "Review of Battery Charger Topologies, Charging Power Levels, and Infrastructure for Plug-In Electric and Hybrid Vehicles," IEEE Transactions on Power Electronics, vol. 28, no. 5, pp. 2151-2169, May 2013.

13. W. Rippel, "Integrated traction inverter and battery charger apparatus," US4920475A, 1990.

14. W. Rippel and A. Cocconi, "Integrated motor drive and recharge system," US5099186A, 1992.

15. A. Cocconi, "Combined motor drive and battery charger system," US5341075A, 1994.

16. G. Albright, J. Edie, and S. Al-Hallaj, "A Comparison of Lead Acid to Lithium-ion in Stationary Storage Applications," AllCell Technologies White Paper, no. March, p. 14, 2012.

17. B. B. McKeon, J. Furukawa, and S. Fenstermacher, "Advanced Lead-Acid Batteries and the Development of Grid-Scale Energy Storage Systems," Proceedings of the IEEE, vol. 102, no. 6, pp. 951-963, Jun. 2014.

18. G. J. May, A. Davidson, and B. Monahov, "Lead batteries for utility energy storage: A review," Journal of Energy Storage, vol. 15, pp. 145-157, Feb. 2018.

19. S. Jinlei, P. Lei, L. Ruihang, M. Qian, T. Chuanyu, and W. Tianru, "Economic Operation Optimization for 2nd Use Batteries in Battery Energy Storage Systems," IEEE Access, vol. 7, pp. 41852-41859, 2019. 